\title{
Editorial
}

\section{Current Updates on High-Risk Human Papilloma Virus Testing for Cervical Cancer Screening}

\author{
S M KHODEZA NAHAR BEGUM ${ }^{1}$
}

High risk HPV (hrHPV) testing has proven utility in both cervical cancer screening and management. Combined cervical cytology and hrHPV testing is now the preferred strategy for women aged $\geq 30$ yrs ${ }^{1}$ American society of colposcopy and cervical pathology (ASCCP) has endorsed screening guidelines in 2013 which states that utilizing contesting extensively is both a sensitive and efficient way to manage and follow these women. ${ }^{2}$

Inappropriate or too frequent screening including hrHPV testing, can lead to increased costs without proven benefit, and may also cause patient harm by over treatment.

2013 statement on Human papilloma virus DNA test utilization recommended by the American college of obstretricians and gynecologists affirms the following clinical suggestions. ${ }^{1,2}$

1. High risk (oncogenic) HPV DNA testing is appropriate in the following circumstances :

A. Routine cervical cancer screening in conjunction with cervical cytology (cotesting) for women aged 30 to $65 \mathrm{yr}$.

i) For women whose cytology and hrHPV results are both negative, both tests may be repeated only after a five year interval.

ii) For women whose cytology results are negative and whose hrHPV test is positive, both tests may be repeated within a year.

B. Follow-up cotesting of women aged $\geq 25$ yrs. with preceding hrHPV negative ASC-US at 3 yrs. as per ASCCP management guidelines. ${ }^{3,4}$

C. Initial triage management of women aged $\geq 30 \mathrm{yrs}$. with low grade squamouse"intraepithelial lesion (LSIL), generally when performed as part of a screening cotest. If test is negative, a repeat cotest should be advised after $1 \mathrm{yr}$.

1. Dr. SM Khodeza Nahar Begum, Associate Professor; Department of Pathology, Anwer Khan Modern Medical College, Dhaka. e-mail: khodeza33@hotmail.com.

Correspondence: Dr. SM Khodeza Nahar Begum, Associate Professor, Department of Pathology, Anwer Khan Modern Medical College, Dhaka. e-mail: khodeza33@hotmail.com.
D. In postmenopausal women hrHPV testing may be ordered as a triage for LSIL. If test is negative, a repeat cotest should be advised after $1 \mathrm{yr}$.

E. Follow up cotesting of women aged $\geq 30$ yrs. at 3 yrs. after previous negative cotestresults with various preceding cytology abnormalities and no evidence of high grade lesion in colposcopy.

2. High risk (oncogenic) HPV testing is generally not appropriate in the following situations:

A. Routine cervical cancer screening in women aged $<30$ yrs.

B. Routine cervical cancer screening with contesting more often than every 5 yrs. When previous cotest results were negative.

C. Initial triage or management of women of aged $<30 \mathrm{yrs}$. With LSIL.

3. Repeat high risk HPV testing should generally not be performed before 12 months.

4. Testing for low -risk (non-oncogenic) HPV types has no role in cervical cancer screening or in the triage, managementor follow-up of women with abnormal cytology results. Following figure is the illustration take from the interim clinical guidance published on Feb., $2015 .^{5}$

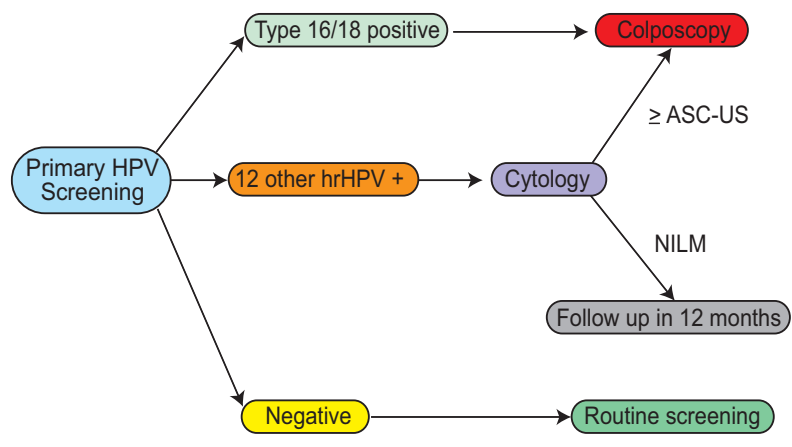

Fig.-1 : Recommended primary HPV screning algorithm ASC-US - Atypical squamous cells of undetermined significance NILM - Negative for intra-epithelial lesion or malignancy 
The intent of this summary is to encourage the appropriate utilization of hrHPV testing. Clinical judgment should always beused when applying a guideline to an individual patient. It may also be mentioned that a negative hrHPV test provides greater reassurance of low CIN3+ risk than a negative cytology result.

Because of equivalent or superior effectiveness, primary hrHPV screening can be considered as an alternative to current cytology-based cervical cancer screening methods.

\section{References:}

1. Committee on practice bulletins-gynecology. ACOG practice bulletin number 131: screening for cervical cancer. Obstet gynecol. 2012;120:1222-1238.

2. US preventive services task force. Screening for cervical cancer uspreventiveservicestaskforce.org/uspstf/uspsccrv. htm AccessedSeptember 18, 2013.
3. Massad IS, Einstein MH,Huh WK, et al. 2012 ASCCP consensus guidelines conference. 2012 updated consensus guideline for the management of abnormalcervical cancer screeningtests and cancer precursors. ObstetGynecol 2013; 121:829-846.

4. Karki HA, Schiffman M, Castle PE etal.Five year risk of CIN 3+ and cervical cancer among women with HPV testing of ASC-US PAP results J low Genit Tract Dis. 2013;17(5 suppl 1): 536-542.

5. Huh WK, Ault KA, Chelmow D, Davey DD, Goulart RA et al. Use of primary high-risk human papillomavirus testing for cervical cancer screening: Interim clinical guidance. Gynecol Oncol. 2015 Feb;136(2):178-82. doi: 10.1016/ j.ygyno.2014.12.022. Epub 2015 Jan 8. 